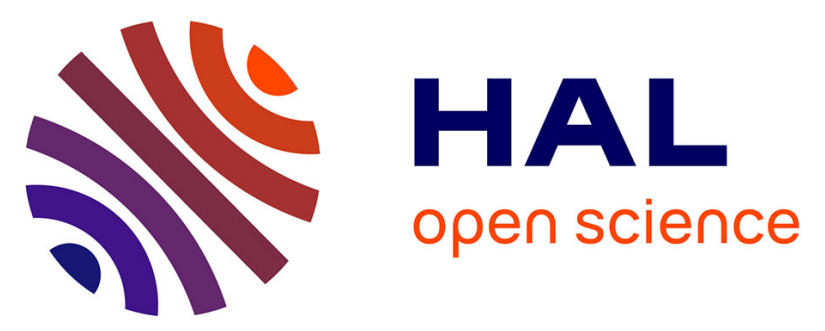

\title{
/ mutation status and clinical-pathologic features of 108 male breast cancer cases from Tuscany: a population-based study in central Italy
}

Laura Ottini, Piera Rizzolo, Ines Zanna, Mario Falchetti, Giovanna Masala, Ketty Ceccarelli, Vania Vezzosi, Alberto Gulino, Giuseppe Giannini, Simonetta Bianchi, et al.

\section{To cite this version:}

Laura Ottini, Piera Rizzolo, Ines Zanna, Mario Falchetti, Giovanna Masala, et al.. / mutation status and clinical-pathologic features of 108 male breast cancer cases from Tuscany: a populationbased study in central Italy. Breast Cancer Research and Treatment, 2008, 116 (3), pp.577-586. 10.1007/s10549-008-0194-z . hal-00478269

\section{HAL Id: hal-00478269 https://hal.science/hal-00478269}

Submitted on 30 Apr 2010

HAL is a multi-disciplinary open access archive for the deposit and dissemination of scientific research documents, whether they are published or not. The documents may come from teaching and research institutions in France or abroad, or from public or private research centers.
L'archive ouverte pluridisciplinaire HAL, est destinée au dépôt et à la diffusion de documents scientifiques de niveau recherche, publiés ou non, émanant des établissements d'enseignement et de recherche français ou étrangers, des laboratoires publics ou privés. 


\title{
$B R C A 1 / B R C A 2$ mutation status and clinical-pathologic features of 108 male breast cancer cases from Tuscany: a population-based study in central Italy
}

\author{
Laura Ottini - Piera Rizzolo - Ines Zanna - Mario Falchetti - Giovanna Masala · \\ Ketty Ceccarelli · Vania Vezzosi - Alberto Gulino - Giuseppe Giannini · \\ Simonetta Bianchi · Francesco Sera · Domenico Palli
}

Received: 10 September 2008/ Accepted: 10 September 2008/Published online: 26 September 2008 (C) Springer Science+Business Media, LLC. 2008

\begin{abstract}
Background Male breast cancer (MBC) is a rare and scarcely investigated disease. The strongest genetic risk factor for $\mathrm{MBC}$ is represented by inherited $B R C A 2$ mutations, whereas the association between $\mathrm{MBC}$ and $B R C A 1$ mutations is less clear. MBC appears to be biologically similar to breast cancer in females, however the phenotypic characteristics of BRCA1/2-related MBCs are not yet well elucidated. Objective To investigate the genetic and phenotypic characteristics of $\mathrm{MBC}$ in a large and wellcharacterized population-based series of $108 \mathrm{MBCs}$ from Tuscany (Central Italy) and to evaluate associations between BRCA1/BRCA2 mutation status and clinical-pathological features including breast/ovarian cancer first-degree family history, tumor histology and grade, proliferative activity, estrogen/progesterone receptors (ER/PR) and epidermal growth factor receptor 2 (HER2) expression. Results $B R C A 1 / B R C A 2$ mutations were identified in ten MBCs, in particular, two cases (1.9\%) carried BRCAl and eight cases (7.4\%) carried BRCA2 mutations. The same BRCAl mutation (3347delAG) was detected in two unrelated MBC cases. Three novel BRCA2 pathogenic mutations were found. Statistically significant associations emerged between BRCA2-related tumors and absence of PR expression
\end{abstract}

L. Ottini $(\bowtie) \cdot$ P. Rizzolo · M. Falchetti - K. Ceccarelli ·

A. Gulino · G. Giannini

Department of Experimental Medicine, University of Rome

"La Sapienza", Viale Regina Elena, 324, 00161 Rome, Italy

e-mail: laura.ottini@uniroma1.it

I. Zanna $\cdot$ G. Masala $\cdot$ F. Sera $\cdot$ D. Palli

Molecular and Nutritional Epidemiology Unit, Cancer Research and Prevention Institute - ISPO, 50139 Florence, Italy

V. Vezzosi · S. Bianchi

Department of Pathology, University of Florence,

50100 Florence, Italy
$(P=0.008)$, HER2 over-expression $(P=0.002)$ and high tumor grade $(P=0.005)$. Conclusions Here, we (i) reported that in our population about $9 \%$ of MBC cases are accounted for by $B R C A 1 / B R C A 2$ mutations; (ii) enlarged the $B R C A 2$ mutational spectrum and (iii) characterized a specific phenotype associated with $B R C A 2$-related MBCs suggestive of aggressive behavior. Overall, our results may have important implications on clinical management for this rare disease.

Keywords Male breast cancer - BRCA1 - BRCA2 . Germ-line mutations · Clinical-pathologic features

\section{Introduction}

Male breast cancer (MBC) is a rare disease, accounting for $<1 \%$ of all cancers in men. However, recent epidemiological studies indicate that its incidence is rising $1.1 \%$ annually [1, 2]. In Europe, the incidence of MBC is 1 in 100,000 men per year, and $<1 \%$ of all breast cancer (BC) patients are male [3]. In Italy, MBC accounts for $0.2 \%$ of all cancers in males and incidence rates, standardized on the European population, are about 1 new case $\times 100,000$ men per year [4].

At the epidemiological level, male and female BC share many similarities with the main differences represented by a lower incidence and older age of occurrence of MBC [5]. Hormonal, environmental and genetic factors are involved in the pathogenesis of $\mathrm{BC}$ in women as well as in men. Major risk factors related to $\mathrm{MBC}$ predisposition include pathological conditions associated with primary and secondary hyper-estrogenism, radiation exposure, and, particularly, a family history $(\mathrm{FH})$ positive for breast and/or ovarian cancer. About $20 \%$ of MBC patients have a first-degree relative 
affected by $\mathrm{BC}$ [3], which points to a relevant genetic component in MBC predisposition. Germ-line mutations of BRCA2 (OMIM \# 600185) and, with lower frequency, of BRCA1 (OMIM \# 113705) are implicated in MBC predisposition. However, the frequency of $B R C A 1$ and $B R C A 2$ mutations are quite different in ethnically diverse population- and clinic-based MBC series, ranging between $4 \%$ and $40 \%$ for $B R C A 2$ and up to $4 \%$ for $B R C A 1$, being higher in the presence of founder effects [6]. $B R C A 1$ and $B R C A 2$ founder mutations have been identified in specific countries or ethnic groups, particularly in genetically isolated populations such as the Icelanders and Ashkenazi Jews. In Italy, there is evidence of founder BRCAI and BRCA2 mutations in regions that show a micro-homogeneity [7-11]. As for the association between $\mathrm{MBC}$ and $B R C A 2$ germ-line mutations, the presence of a male affected by $\mathrm{BC}$ seems to be the strongest predictor for the occurrence of $B R C A 2$ genomic rearrangements in high-risk families. Indeed, $B R C A 2$ rearrangements are observed in about $10 \%$ of $\mathrm{MBC}$ families negative for BRCAl/2 point mutations, whereas BRCAl rearrangements are rarely found [12-16]. On the other hand, we recently reported that both $B R C A 2$ and $B R C A 1$ rearrangements are infrequent in $\mathrm{MBC}$ cases, negative for BRCA1/2 mutations, unselected by FH [17].

Male breast cancer and female breast cancer (FBC) appear to be biologically similar but they differ mainly in the frequency of histological types and in the expression of hormone receptors (estrogen/progesterone, ER/PR) and of epidermal growth factor receptor 2 (HER2). In MBC, the predominant histological type is invasive ductal carcinoma, which characterizes more than $90 \%$ of all MBC cases [18]. MBC shows higher rates of ER/PR positivity (ER/PR+) and lesser rate of HER2 over-expression (HER2+), compared with $\mathrm{FBC}[3,5,6]$. Accumulating evidence supports that BRCA1 and BRCA2-related FBC tend to manifest specific phenotypic profiles [19]. In particular, BRCA1tumors tend to be ER-, PR- and HER2-negative (triple negative) and BRCA2-tumors tend to be more often ER/ PR+ and HER2- [20]. At present, very few data are available for $B R C A 1 / 2$-related MBC [21]. Indeed, due to its rarity, $\mathrm{MBC}$ is less investigated compared to $\mathrm{FBC}$, but it is now receiving more attention, probably because of its increasing incidence and of the better knowledge on the role of BRCA genes mutations in MBC predisposition. Retrospective studies on large series of MBC have been recently performed to investigate the major clinical-pathologic characteristics of $\mathrm{BC}$ in men $[18,22]$; however, these studies did not report data on BRCA1/2 mutation status. On the other hand, studies concerning BRCA1/2 mutation screening are often limited in the number of cases analyzed. To our knowledge, very few studies have been performed in MBC series of more than 100 cases and the screening was limited to founder mutations [23, 24].
The present study was carried out with the aim to characterize the genetic and phenotypic features of MBC from a large and epidemiologically well-characterized population-based series from Tuscany (Central Italy). In particular, we wished (i) to assess the prevalence and spectrum of BRCAl and BRCA2 mutations and (ii) to investigate the phenotypic features of tumors in order to further characterize BRCA1/2-related MBCs.

\section{Patients and methods}

\section{MBC patients}

In the present study, we expanded the original populationbased series of $25 \mathrm{MBC}$ cases diagnosed in the area of Florence (Tuscany, Central Italy) in the period 19901998, that we have previously described [25], based on all currently available local sources (including Pathology Departments and the Hospital Discharge database). We enrolled 83 additional MBC cases, diagnosed in the period 1991-2007, for a total of 108 MBCs residing in Eastern Tuscany. The recruitment of the new MBC cases was carried out according to the same protocol as used for the previous MBC series. Overall, after exclusion of deceased and migrated patients, 94 additional unrelated MBC were traced and invited to participate into the study. Eleven cases refused to participate, mostly because of advanced age or severe illness, thus confirming our previous high response rate $(83 / 94,88.3 \%)$. For each study participant we obtained: (i) a signed informed consent form with a detailed description of the study protocol, including the information about the mutational analysis of the BRCA1/BRCA2 genes; (ii) detailed information on his FH for cancer at any sites, including all first- and seconddegree relatives of both genders (all of this information was validated by available sources, mainly local Cancer and Mortality Registries); (iii) detailed information on his personal history of cancer at any site; (iv) information on life style habits and a detailed occupational history up to the date of $\mathrm{BC}$ diagnosis; (v) one or more blood sample(s). All information were collected by a genetician in the frame of the High-Risk Cancer Family Project. The a priori probability of carrying a mutation in the BRCA1/2 genes was estimated by using the BRCAPRO software version 4.2 [26]. Pathological reports and histological slides for all of the MBC cases were identified and retrieved from the archival files of the Pathology Departments of the area for diagnostic confirmation. Procedures to maintain confidentiality for all the information collected were developed and strictly applied. The study was approved by the Florence Ethical Research Committee. 
Mutational analysis

The entire BRCA1 and BRCA2 coding sequences were screened for germ-line mutations. After isolation of genomic DNA from buffy coats, PCR-amplified BRCAl exons 2-10 and $12-24$ and BRCA2 exons $2-9$ and $12-27$ were analyzed by combining single strand conformational polymorphism (SSCP) and automatic sequencing with the ABI Prism-310 Genetic Analyzer (Applied Biosystems, Warrington, UK). The larger exons (BRCAl exon 11, $B R C A 2$ exons 10 and 11) were rapidly screened for truncating mutations by the protein truncation test (PTT) or by automatic sequencing analysis in cases negative for truncating mutations within these exons. Mutations were verified on two independent blood samples. The DNA mutation nomenclature is as used in the Breast Information Core (BIC) database (http://research.nghgri.nih.gov/bic) according to GenBank, U14680.1 and U43746 for BRCA1 and $B R C A 2$, respectively. Novel $B R C A 1 / 2$ variant sequences were analysed in silico for predicted splicing defects by using SpliceSiteFinder (http://www.genet.sickkids.on.ca/ ali/spilcesitefinder.html) and ESEfinder (http://rulai.cshl. edu/tools/ESE3/). Intronic variants predicted to alter RNA splicing were further analysed by RT-PCR, carried out using Superscript II (Invitrogen, Carlsbad, CA, USA) reverse transcriptase with gene-specific primers for the cDNA. Total RNA was extracted from peripheral blood leukocytes by using Trizol Reagent and following manufacturer instructions (Invitrogen, Carlsbad, CA, USA).

\section{Haplotype analysis}

A total of 10 individuals belonging to the two families segregating the recurrent BRCAl 3347delAG mutation and 14 population controls were genotyped at six microsatellite markers, including three intragenic loci (D17S1323, D17S1322 and D17S855, located in BRCA1 intron 12, 19 and 20, respectively), one centromeric (D17S250) and two telomeric (D17S858 and D17S1183) markers. The haplotype analysis encompassed a distance of about $1,332 \mathrm{~Kb}$ between the D17S855 and D17S1183 markers. Alleles were numbered according to the size of each microsatellite repeat marker. The disease-associated haplotypes were deduced by inspection of segregating genotypes in the analyzed individuals.

\section{Immunohistochemical analysis}

Step sections from formalin-fixed, paraffin-embedded primary mammary tumor blocks were obtained for the majority of the cases in order to perform ad hoc immunohistochemical analyses. Overall, out of 110 tumors in 108 patients, we obtained tissue blocks for 96 tumors in 94 patients (including two blocks each for two bilateral MBCs and only one for the other bilateral case). Immunohistochemical studies were performed on 96 available formalinfixed paraffin-embedded tissue blocks of 94 patients (out of the original 108 cases; including 5 blocks of 3 patients with bilateral BC). Immuno-histochemical data could not be obtained for some of these MBCs because available tissue specimens were not sufficient for the whole study protocol. Markers were thus available for a variable number of tumors (range 90-96). The following primary antibodies were applied: anti-HER2, clone TAB 250 (Zymed, S. Francisco, CA), diluted 1:20; anti-ER, clone 6F11 (Ventana Medical Systems, Tucson, AZ) prediluted; anti-PR, clone 1A6 (Ventana Medical Systems, Tucson, AZ) prediluted and anti-Ki-67, clone MIB1 (Dako Cytomation, Glostrup, DK) diluted 1:60. Immunoistochemical protocols and scoring procedures have been described in detail elsewhere $[25,27]$.

Statistical analysis

The association between mutation carrier status and firstdegree FH of breast/ovarian cancer was measured by calculating the prevalence rate ratio and its $95 \% \mathrm{CI}$. The association between mutation carrier status and PR, ER, HER2 or MIB1 immuno-histochemical expression was tested by using the Fisher exact test. The association between mutation carrier status and histopathological grade was tested using the Wald test of the coefficient associated with histopathological grade and considered as continuous variables in a logistic regression analysis with mutation carrier status as outcome. A $P$ value $<0.05$ was considered statistically significant. All the analyses were carried out by using the SAS statistical software (SAS/STAT version 9.1).

\section{Results}

Prevalence and spectrum of $B R C A 1$ and $B R C A 2$ mutation in a population-based series of Italian MBC cases

To evaluate the contribution of BRCAl and BRCA2 mutations in MBC we enrolled a large and well-characterized population-based series of $108 \mathrm{MBC}$ cases, diagnosed in the period 1991-2007 in the area of Florence (Tuscany, Central Italy), thus expanding our previous study based on 25 MBCs [25]. In the present population-based series, age at first $\mathrm{BC}$ diagnosis ranged between 24 and 90 years (mean: 63.2 years; median: 65.0 years). Overall, $25.9 \%$ of the patients reported a first-degree FH of breast/ ovarian cancer (Table 1), including one patient with a firstdegree FH of MBC. Furthermore, 37 patients (34.3\%) had 
a first-degree FH of cancer at sites other than breast/ovary, including nine patients $(8.3 \%)$ that reported both a firstdegree $\mathrm{FH}$ of breast/ovarian cancer and of cancer at other sites. A personal history of cancer(s) at sites other than breast was reported in $14.8 \%$ of MBC cases (Table 1). In these patients prostate and bladder carcinomas were the most frequently observed metachronous cancers. Notably, three out of 108 MBC patients had been diagnosed with bilateral BC. With regard to the pathological characteristics of the MBC cases (Table 1), the majority of the tumors was invasive ductal carcinomas (78.2\%), expressed ER (ER+, 87.5\%) and PR (PR+, 79.2\%), showed low proliferative activity (MIB1-, 65.6\%) and did not over-express HER2 (HER2-, 81.3\%).

Overall, deleterious $B R C A 1 / 2$ germ-line mutations were detected in 10 of the $108 \mathrm{MBC}$ cases analyzed, with a mutation prevalence of $9.3 \%$ (95\% CI, 4-15\%). In particular, two cases $(1.9 \%, 95 \% \mathrm{CI}, 0-4 \%)$ carried $B R C A l$ and eight cases $(7.4 \%, 95 \%$ CI, 2-12\%) carried BRCA2 mutations (Table 2). The same BRCAl mutation (3347delAG) was identified in two unrelated MBC cases (Fig. 1). Haplotype analysis allowed the identification of a common haplotype shared by all mutation carriers (seven individuals) but not by non carrier relatives (three individuals). The same analysis conducted in 14 healthy controls revealed strong allele variability and different allele pattern compared to the carriers belonging to the BRCA1 3347delAG families (data not shown). As shown in Table 2, of the eight BRCA2 mutations here identified three are novel mutations not reported in the BIC database (http://research. nghgri.nih.gov/bic). Two of them, the BRCA2 802insA and the BRCA2 7935delT, are frameshift mutations that create a stop at codons 205 and 2647, respectively (Table 2, Fig. 2). The third novel mutation, the BRCA2 IVS7-2 $A>G$, is an intronic variant. By in silico analysis, the BRCA2 IVS7-2 $\mathrm{A}>\mathrm{G}$ is predicted to affect the splicing of exon 8 by disrupting the intron 7 acceptor site (SpliceSiteFinder wild type efficiency score $=93.4$ ) and the exonic splice enhancer SRp40 motif (ESEfinder wild type efficiency score $=3.63$ ). We evaluated the consequence of the BRCA2 IVS7-2 A $>\mathrm{G}$ variant on splicing in vivo by examining RNA isolated from peripheral lymphocytes of the MBC patient (MB 115) carrying the variant. RT-PCR, performed to amplify a region encompassing $B R C A 2$ exons 6-9 produced two cDNA fragments: one of the predicted size (314 bp) for the wild type product and the other approximately $50 \mathrm{bp}$ smaller than the wild type cDNA product (Fig. 3). Direct sequence analysis of the abnormal PCR product showed a transcript lacking exon 8 (BRCA2 860-909del) and containing a stop signal at codon 236.

By using the BRCAPRO software version 4.2 [26], the a priori probability of carrying a mutation in $B R C A 1 / 2$ was estimated for all cases (mean value: $23.8 \%$; range: $0-100 \%$ ).
Table 1 Clinico-pathological characteristics of 110 tumors from the population-based series of 108 Italian MBC cases (Florence 1990-2007)

\begin{tabular}{|c|c|}
\hline Clinico-pathological characteristics & $N(\%)^{\mathrm{a}}$ \\
\hline \multicolumn{2}{|l|}{ Family history of breast/ovarian cancer } \\
\hline Negative & $80(74.1)$ \\
\hline Positive & $28(25.9)$ \\
\hline Total & 108 \\
\hline \multicolumn{2}{|l|}{ Personal history of cancer } \\
\hline Negative & $92(85.2)$ \\
\hline Positive & $16(14.8)$ \\
\hline Total & 108 \\
\hline \multicolumn{2}{|l|}{ Histology } \\
\hline Invasive ductal carcinoma & $86(78.2)$ \\
\hline In situ ductal carcinoma & $8(7.3)$ \\
\hline Papillary carcinoma & $6(5.5)$ \\
\hline Mucinous (colloid) & $1(0.9)$ \\
\hline Lobular carcinoma & $3(2.7)$ \\
\hline Paget's & $2(1.8)$ \\
\hline Adenoid cystic carcinomas & $2(1.8)$ \\
\hline Cribriform carcinoma & $2(1.8)$ \\
\hline Total & 110 \\
\hline \multicolumn{2}{|l|}{ Grade } \\
\hline G1 & $18(19.0)$ \\
\hline G2 & $50(52.6)$ \\
\hline G3 & $27(28.4)$ \\
\hline Total & 95 \\
\hline \multicolumn{2}{|l|}{ Stage } \\
\hline 0 & $10(12.0)$ \\
\hline I & $31(37.4)$ \\
\hline II & $30(36.1)$ \\
\hline III-IV & $12(14.5)$ \\
\hline Total & 83 \\
\hline \multicolumn{2}{|l|}{ ER } \\
\hline Negative & $12(12.5)$ \\
\hline Positive & $84(87.5)$ \\
\hline Total & 96 \\
\hline \multicolumn{2}{|l|}{ PR } \\
\hline Negative & $20(20.8)$ \\
\hline Positive & $76(79.2)$ \\
\hline Total & 96 \\
\hline \multicolumn{2}{|l|}{ MIB1 } \\
\hline Negative & 59 (65.6) \\
\hline Positive & $31(34.4)$ \\
\hline Total & 90 \\
\hline \multicolumn{2}{|l|}{ HER2 } \\
\hline Negative & $74(81.3)$ \\
\hline Positive & 17 (18.7) \\
\hline Total & 91 \\
\hline
\end{tabular}

\footnotetext{
${ }^{a}$ Frequencies were calculated excluding tumors with information not available for specific variables because of lack of tissue samples; two patients with bilateral BC (out of the three identified) were considered separately for each tumor
}

All BRCA1/2 deleterious mutations were detected in the 65 cases with an a priori probability above $10 \%$ (expected versus observed: 36.4 and $15.4 \%$, respectively) and none in 
Table 2 Personal and family history of cancer, pathologic characteristics and immunohistochemical staining for ER, PR, HER2 and MIB1 in the BRCA1/2 MBC mutation carriers (Florence, Italy 1990-2007)

\begin{tabular}{|c|c|c|c|c|c|c|c|c|c|c|}
\hline \multirow[t]{2}{*}{ Gene } & \multirow[t]{2}{*}{ Mutations $^{\mathrm{a}}$} & \multirow[t]{2}{*}{ Mutation effect } & \multirow[t]{2}{*}{ Case code } & \multirow{2}{*}{$\begin{array}{l}\text { Personal history } \\
\text { of breast cancer } \\
\text { (age at diagnosis, } \\
\text { year) }\end{array}$} & \multirow{2}{*}{$\begin{array}{l}\text { Breast/ovarian cancer in } \\
\text { first-degree relatives } \\
\text { (age at diagnosis, year) }\end{array}$} & \multirow{2}{*}{$\begin{array}{l}\text { Histology/ } \\
\text { Grade }\end{array}$} & \multicolumn{4}{|c|}{ Immunostaining } \\
\hline & & & & & & & ER & PR & HER 2 & MIB1 \\
\hline \multirow[t]{2}{*}{$B R C A 1$} & 3347delAG & R1076fs1084X & $\mathrm{MB} 5^{\mathrm{b}}$ & 60 & 2 Breast $(45,41)$ & $\mathrm{IDC} / 3$ & + & + & - & - \\
\hline & 3347delAG & R1076fs1084X & MB 56 & 55 & & ILC & - & - & - & + \\
\hline \multirow[t]{8}{*}{$B R C A 2$} & 802insA & M192fs205X & MB 83 & 70 & & $\mathrm{IDC} / 2$ & + & + & - & na \\
\hline & IVS7-2A $>$ G & Exon 8 skipping & MB 115 & 41 & & $\mathrm{IDC} / 3$ & + & - & + & - \\
\hline & 1003 delA & R259fs $276 X$ & $\mathrm{MB} 16^{\mathrm{b}}$ & 64 & & Papillary/3 & - & - & + & + \\
\hline & 2041 ins A & I605fs615X & MB 103 & 44 & Breast (54) & $\mathrm{IDC} / 3$ & - & - & + & - \\
\hline & 5301insA & W1691fs1694X & MB 90 & 57 & & $\mathrm{IDC} / 2$ & + & - & - & + \\
\hline & $6010 \mathrm{G}>\mathrm{T}$ & E1928X & $\mathrm{MB} 31^{\mathrm{b}}$ & 53 & 3 Breast $(48,45$, na) & Paget's/3 & - & - & + & + \\
\hline & 6696delTC & S2156fs2174X & $\mathrm{MB} 3^{\mathrm{b}}$ & 63 & Ovary (62) & $\mathrm{IDC} / 3$ & + & + & + & - \\
\hline & 7935delT & G2569fs2647X & $\mathrm{MB} 89^{\mathrm{c}}$ & $74-77$ & Breast (41), ovary (58) & $\mathrm{IDC} / 3$ & + & + & na & na \\
\hline
\end{tabular}

$I D C$ invasive ductal carcinoma, ILC invasive lobular carcinoma; na not available

${ }^{\mathrm{a}}$ Novel mutations are reported in bold; ${ }^{\mathrm{b}}$ cases reported in our previous study [25]; ${ }^{\mathrm{c}}$ bilateral BC

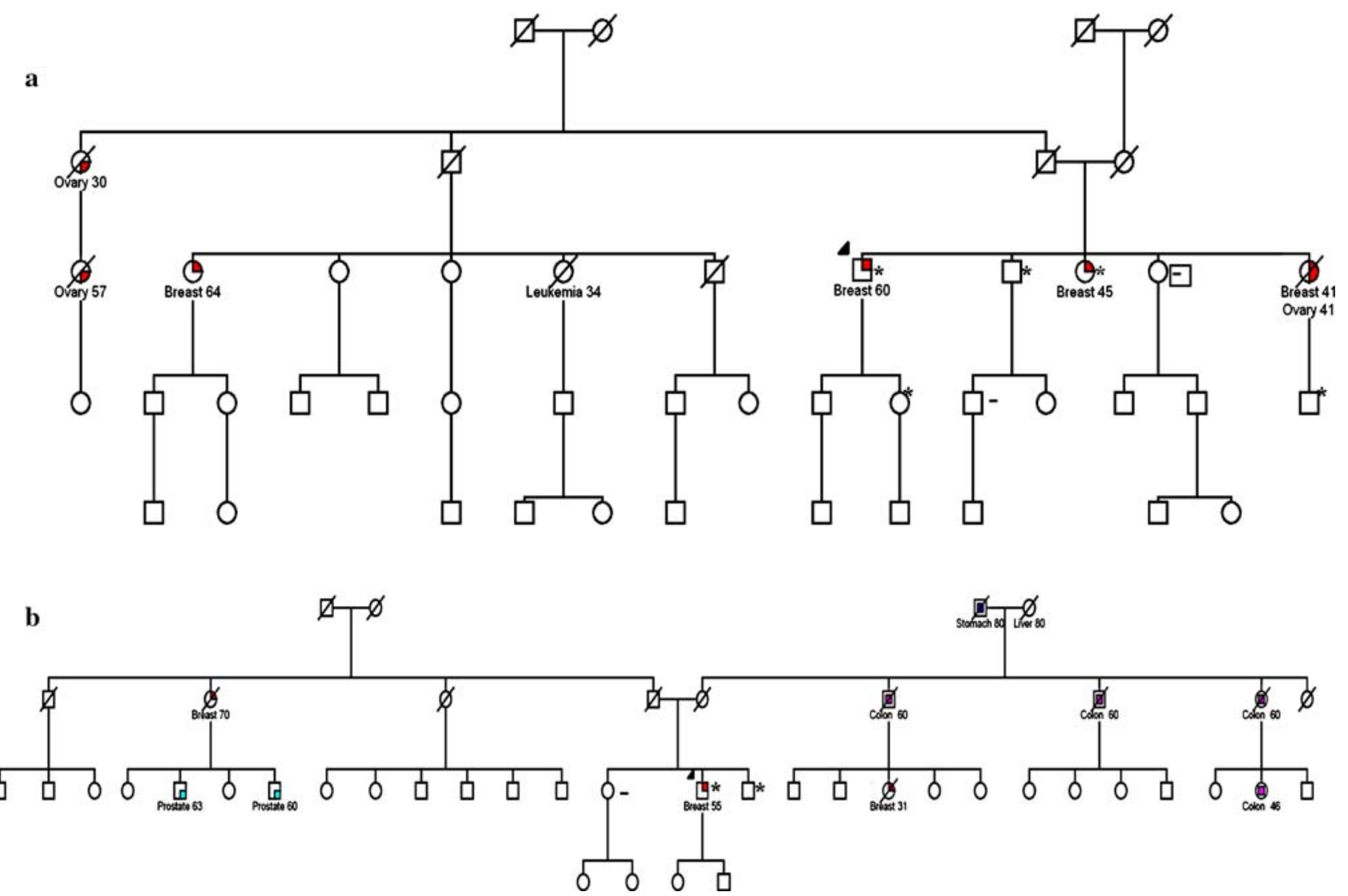

Fig. 1 Pedigrees of the two families carrying the BRCA1 3347delAG germ-line mutation. Probands MB5 (a) and MB56 (b), are indicated by arrows; *: Mutation carrier; -: non carrier

the 43 cases with an a priori probability below $10 \%$ (expected versus observed: 4.9 and $0 \%$, respectively). In particular, we identified $B R C A 1 / 2$ mutations in 3 of the 6 MBC patients with an a priori probability above $80 \%$ (expected versus observed: 95.3 and $50.0 \%$, respectively). Indeed, one MBC case with a BRCAPRO 4.2 of $100 \%$ was shown to carry a mutation in $p 53$, the main gene associated with Li-Fraumeni syndrome (data not shown). 
a

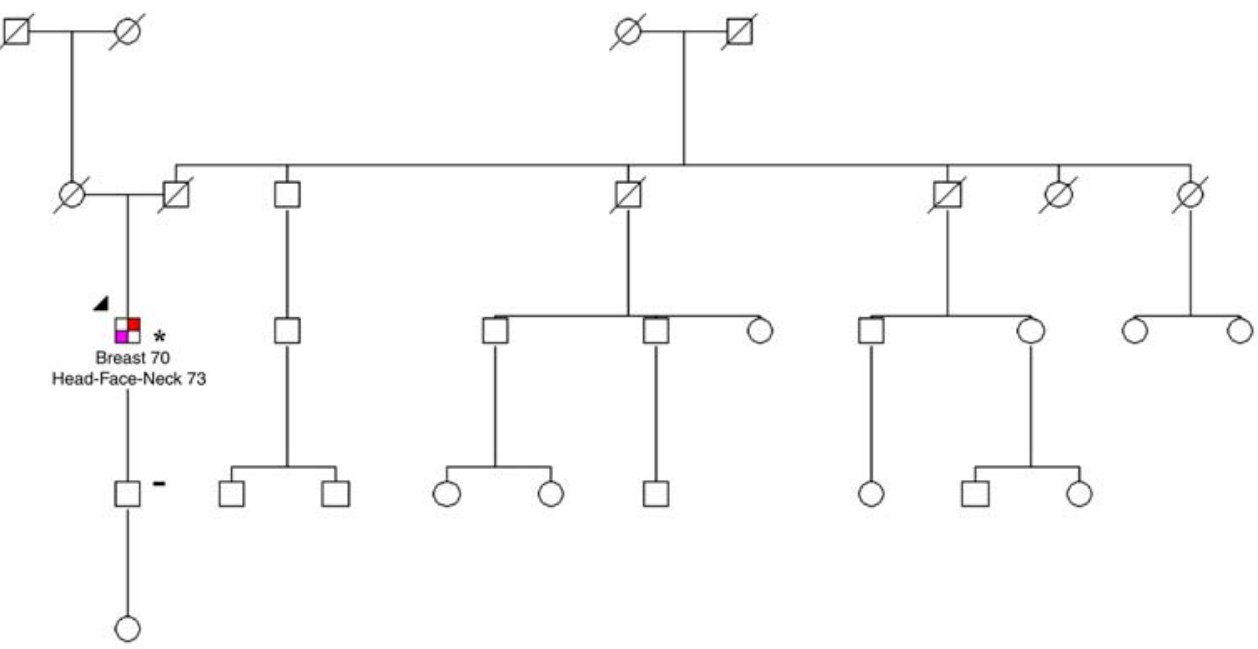

\section{b}

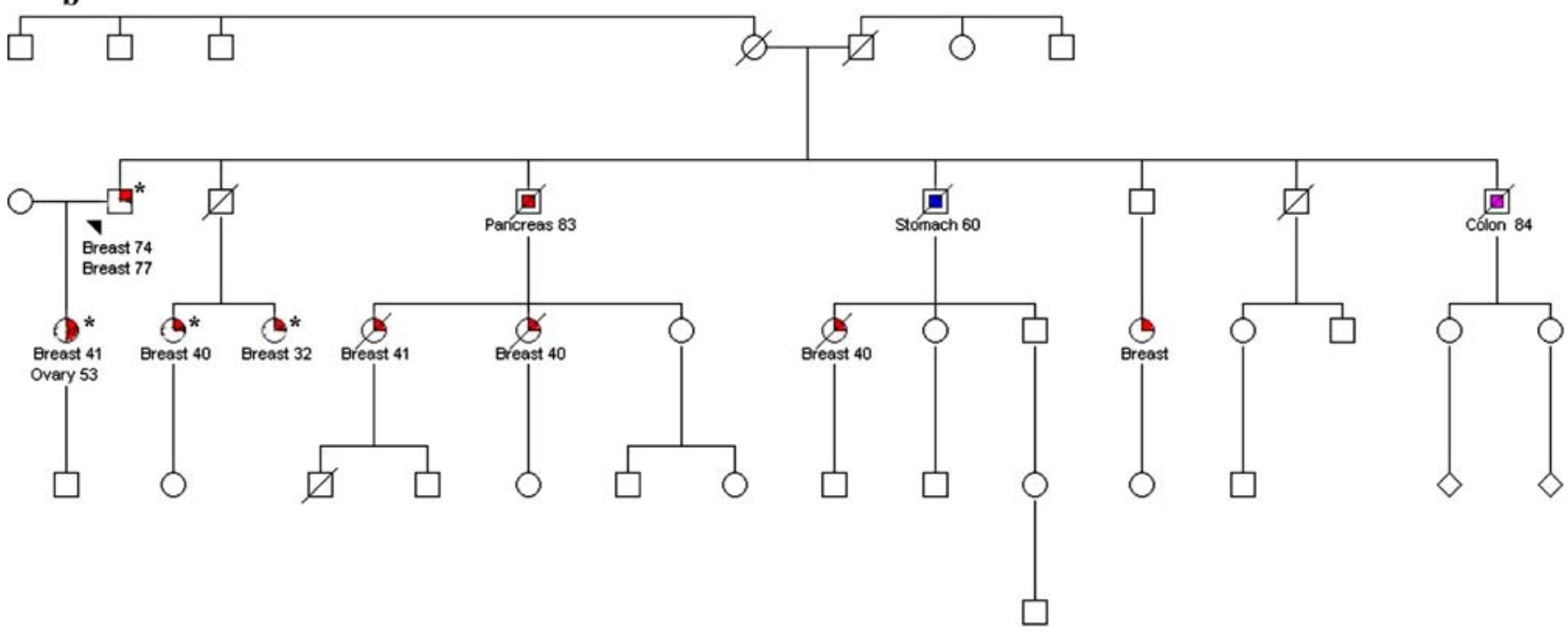

Fig. 2 Pedigrees of families carrying two novel BRCA2 germ-line mutations: BRCA2 802insA (a) and BRCA2 7935delT (b). Probands, MB83 (a) and MB89 (b), are indicated by arrows. *: Mutation carrier; -: non carrier

Clinical-pathologic characteristics and associations with $B R C A 1$ and $B R C A 2$ mutation status

To further characterize BRCA1/2-related MBCs we analyzed the phenotypic features of tumors and investigated the associations between clinical-pathologic characteristics and mutation status. The median age at $\mathrm{BC}$ diagnosis among BRCA1/2 mutation carriers tended to be lower than that among cases in which mutations were not detected (median: 58.5 years; range: 41-77 years, vs. median: 66.3 years; range: $24-90$ years). With regard to firstdegree $\mathrm{FH}$ of breast/ovarian cancer, 5 of the $10(50.0 \%)$ BRCA1/2 mutation carriers reported a positive FH. Overall, 5 out of $28(17.9 \%)$ MBCs with a positive FH and 5 out of $80(6.3 \%)$ MBCs with a negative FH carried BRCA1/2 mutations, with a threefold association emerging between a positive $\mathrm{FH}$ and carrier status: the point estimate of the prevalence rate ratio was 2.86 , falling short of the level of statistical significance (95\% CI, 0.89-9.14). With regard to pathologic characteristics, of the two BRCAl-tumors, one was an invasive ductal carcinoma, $\mathrm{ER}+, \mathrm{PR}+, \mathrm{HER} 2-$ and MIB1-, and the other was a lobular carcinoma, ER-, PR-, HER2- and MIB1+ (Table 2). Overall, of the two BRCA1-tumors one resulted with a triple negative (ER-, PR-, HER2-) phenotype. The majority of the BRCA2-tumors were invasive ductal carcinomas $(75 \%, 6 / 8)$ and were of high grade $(75 \%, 6 / 8)$, $62.5 \%(5 / 8)$ were $\mathrm{ER}+, 62.5 \%(5 / 8)$ were $\mathrm{PR}-, 50 \%(3 / 6)$ were MIB+ and $71.4 \%$ (5/7) were HER2+ (Table 2). We further investigated whether BRCA2-related MBCs showed specific phenotypic profiles by analyzing associations between BRCA2 mutation status and pathological characteristics (Table 3). Statistically significant associations emerged between BRCA2 mutations and absence of PR expression $(P=0.008)$, positive HER2 immunostaining $(P=0.002)$ and high tumor grade $(P=0.005)$. No 
Fig. 3 Transcript

characterization of the $B R C A 2$

IVS7-2G $>$ A variant. a RT-PCR products, visualized on

ethidium-stained agarose gel, showed a smaller cDNA

fragment (arrow) from RNA of the patient carrying the $B R C A 2$ IVS7-2G $>A$ variant compared to control cDNAs; $\mathbf{b}$ sequencing analysis of the abnormal PCR product showed loss of exon 8 ; c graphic model of the effect of $B R C A 2$ IVS7-2G $>$ A variant

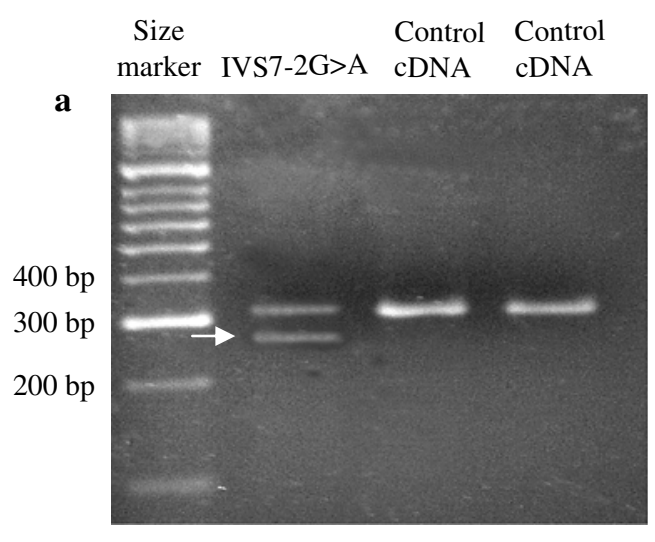

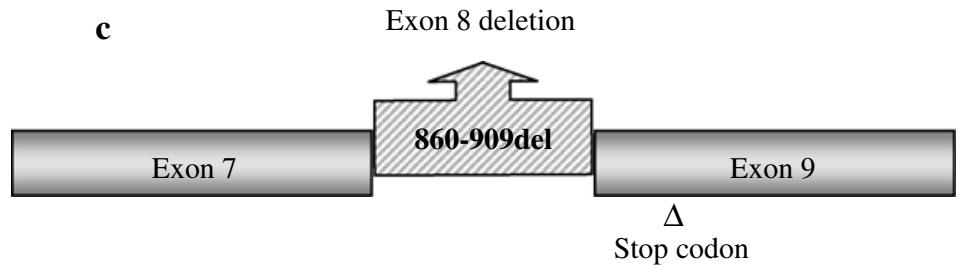

Table 3 Association between selected pathological characteristics and $B R C A 2$ mutation status in MBCs (Florence, Italy 1990-2007)

* Fisher exact test

a The 2 BRCA1 mutation carriers were excluded from this analysis

\begin{tabular}{|c|c|c|c|}
\hline Parameter & $\begin{array}{l}B R C A 1 / 2 \text { wild type }{ }^{\mathrm{a}} \\
N(\%)\end{array}$ & $\begin{array}{l}B R C A 2 \text { mutation } \\
N(\%)\end{array}$ & $P$ value* \\
\hline \multicolumn{4}{|l|}{ Grade } \\
\hline $\mathrm{G} 1+2$ & $66(76.7)$ & $2(25.0)$ & \multirow[t]{3}{*}{0.005} \\
\hline G3 & $20(23.3)$ & $6(75.0)$ & \\
\hline Total & 86 & 8 & \\
\hline \multicolumn{4}{|l|}{ ER } \\
\hline Negative & $8(9.3)$ & $3(37.5)$ & \multirow[t]{3}{*}{0.05} \\
\hline Positive & $78(90.7)$ & $5(62.5)$ & \\
\hline Total & 86 & 8 & \\
\hline \multicolumn{4}{|l|}{ PR } \\
\hline Negative & $14(16.3)$ & $5(62.5)$ & \multirow[t]{3}{*}{0.008} \\
\hline Positive & 72 (83.7) & $3(37.5)$ & \\
\hline Total & 86 & 8 & \\
\hline \multicolumn{4}{|l|}{ MIB1 } \\
\hline Negative & $54(68.4)$ & $3(50.0)$ & \multirow[t]{3}{*}{0.39} \\
\hline Positive & 25 (31.6) & $3(50.0)$ & \\
\hline Total & 79 & 6 & \\
\hline \multicolumn{4}{|l|}{ HER 2} \\
\hline Negative & $70(85.4)$ & $2(28.6)$ & \multirow[t]{3}{*}{0.002} \\
\hline Positive & 12 (14.6) & 5 (71.4) & \\
\hline Total & 82 & 7 & \\
\hline
\end{tabular}

statistically significant association was found between BRCA2 mutations and other clinical-pathological characteristics analyzed, including ER and MIB1 expression. Overall, a specific phenotypic profile, characterized by $\mathrm{PR}-$, HER2 + and high tumor grade, emerged for BRCA2related $\mathrm{MBCs}$.

\section{Discussion}

Here, we report the results of a large population-based study of 108 Italian MBC cases, from Tuscany (Central Italy), performed to investigate the prevalence and spectrum of BRCA1/2 germ-line mutations and to characterize 
the phenotypic features of $B R C A 1 / 2$-related and unrelated MBCs.

Overall, the BRCA1/2 mutations prevalence (9.3\%) observed in our population-based series is comparable with those reported in MBCs unselected by FH from other different populations [23, 28-30]. Although BRCA2 mutations are currently considered as the major genetic risk factor for $\mathrm{MBC}$, the association between MBC and BRCAl mutations is not as well established [3]. BRCA1 mutations are quite rare in unselected $\mathrm{MBC}$ cases being more frequent in specific populations in which a founder effect is known to occur [6]. Notably, the same BRCAl mutation (3347delAG), represented the overall BRCAl mutation frequency $(1.9 \%)$ in the present study. We recently reported that the BRCA1 3347delAG is a founder mutation in Tuscany [31], thus confirming that unselected series of cases from specific geographic areas may lead to the identification of BRCA1/2 mutation with founder effect in genetically heterogeneous countries, such as Italy.

Of the 10 mutations identified in our MBC series, three, including two BRCA2 frameshift mutations (802insA and 7935delT) and a $B R C A 2$ intronic variant (IVS7-2 A>G), were novel alterations not reported in the BIC database (http://research.nghgri.nih.gov/bic). We demonstrated, by characterizing the transcript produced from RNA of the MBC patient carrying the variant, that the BRCA2 IVS7-2 $A>G$ is a novel splice site deleterious mutation causing loss of BRCA2 exon 8 and creating a premature stop codon. In this respect, it is noteworthy that about $4 \%$ of the genetic variants in the BIC database are reported as splice site alterations. Overall, in the present study, we enlarged the mutational spectrum of BRCA2 gene and provided further data to contribute to the discussion on the causal role and clinical relevance of intronic variants.

As we recently observed in FBC [32], when considering the frequency of mutations in $\mathrm{MBC}$ cases stratified according to BRCAPRO 4.2, the prediction accuracy improves as the threshold probability increases. Indeed, we found that $66.6 \%$ of $\mathrm{MBC}$ patients with probability prediction $\geq 80 \%$ have mutations in the $B R C A 1 / 2$ genes and in other genes, such as $p 53$. However, a degree of over-estimation is evident. Despite the comprehensive scan of the coding sequence and the intron-exon boundaries there remains a substantial chance of missed BRCA1/2 genetic alterations possibly due to mutations in other regions of the genes or due to genomic rearrangements. In this respect, it is noteworthy that we recently shown that no BRCA1/2 rearrangements were found in a large series of Italian MBCs, including 72 mutation-negative MBC cases from the population-based series here analyzed [17]. Thus, the data reported in the present study reflect the overall population prevalence of BRCA1/2 mutations in Italian MBC cases. Given the reasonably high sensitivity of our screening and the sample size, our results indicate that, at population level, a large fraction of MBC cases are not accounted for by BRCA1/2 alterations. Collaborative studies are essential to better investigate the pathogenesis of $\mathrm{MBC}$, and, in this context, MBC cases in our series may be useful in identifying new genes predisposing to moderate/high MBC risk. From a clinical point of view, our data suggest that probands with a high $(\geq 80 \%)$ carrier probability prediction have to be considered as carriers of a strongly predisposing genetic alteration either in BRCA1/2 genes or in other yet unknown $\mathrm{BC}$ predisposing genes, independently of our ability to detect such mutations.

Consistent with published data on MBC from diverse populations $[3,23,28]$, in our population-based series, the mean age of $\mathrm{BC}$ presentation in males was 63 years and about one-fourth of MBC cases reported a first-degree BC$\mathrm{FH}$, thus indicating that our series is representative of a standard MBC population and suggesting that data obtained analyzing the present series can be relevant for $\mathrm{MBC}$ in general. We observed that the median age at $\mathrm{BC}$ diagnosis among BRCA1/2 mutation carriers tended to be younger (median: 58.5 years) than that of negative cases (median: 66.3 years). BRCA1/2 mutations were more prevalent in men with a positive first-degree FH (17.9\%) compared with those without $(6.3 \%)$ and a threefold association emerged between a positive $\mathrm{FH}$ and carrier status, falling short of the level of statistical significance. It has been previously reported that BRCAI/2 mutations are more frequent in MBCs with a positive $\mathrm{FH}[23,29,33]$. However, in our series, $50 \%$ of the mutations were identified in MBC cases without $\mathrm{FH}$, thus from a clinical point of view, our data indicate that mutation screening is beneficial also among isolated MBC cases.

With regard to pathological characteristics of the tumors, in our series the majority of breast tumors were invasive ductal carcinomas and express ER/PR, whereas only a minority over-expresses HER2. Overall, our results are consistent with retrospective studies on large MBC series performed to characterize the major phenotypic features of $\mathrm{BC}$ in males $(18,21)$. To further investigate the pathological features of $\mathrm{BC}$ in men, we also examined the proliferative activity of MBCs by immunohistochemical evaluation of MIB1. Proliferative activity is considered an important prognostic factor in FBC, but it has been scarcely investigated in MBC and data are often inconsistent, most likely because of the small number of cases examined [34, 35]. Our results showed that about $34 \%$ of MBCs exhibit a high proliferative activity (MIB1+). At present, little is known of the immunophenotypic characteristics of MBCs stratified according to BRCA1/2 mutation status [21]. Notably, one of the two BRCAl-related MBC, identified in our series, showed a triple negative phenotype (ER-, PR-, HER2-) consistent with what observed in BRCAl-related breast 
tumors in females [19]. Furthermore, we observed that $B R C A 2$-related MBCs showed a significant association with HER2 over-expression and with a high tumor grade, thus confirming on a large number of cases what we have previously reported [25]. Intriguingly, we found that BRCA2related MBC tended to be negative for PR expression. Taking into account that MBCs are predominantly PR+ and HER2-, our findings suggest that specific phenotypic characteristics are associated with BRCA2-linked MBCs. These findings may be relevant on a clinical ground considering that a tumor phenotype characterized by PR-, HER2+ and high grade may be indicative of aggressive behavior. Furthermore, our results may be also relevant for the treatment of $\mathrm{MBC}$, by providing data on biomarkers useful to determine the subset of MBC patients (PR-, HER2+) that will benefit from trastuzumab therapy. Overall, our observations may have important prognostic and therapeutic implications and warrant to be replicated in larger collaborative investigations of this rare disease.

Acknowledgments Authors are grateful to all patients, their families and their caring physicians for participating in this study. Authors wish also to thank Mr. Massimo Zani and Mr. Sergio Ferraro for expert technical assistance, and all the colleagues of the Pathology Departments of several hospitals in the study area (Drs. Carmelo Urso, Augusto Giannini, Lavinia Puglisi, Tiziana Megha, Michela Stumpo, Federica Zolfanelli, Francesco Mirri, Lidia La Magra, and Mauro Biancalani) for their active collaboration in providing tissue samples. The study was supported by a grant from Associazione Italiana per la Ricerca sul Cancro (AIRC) to Laura Ottini and by Regione Toscana in the frame of the High-Risk Cancer Family Project.

\section{References}

1. NCI, SEER (Surveillance Epidemiology and End Results) database 2007

2. Speirs V, Shaaban AM (2008) The rising incidence of male breast cancer. Breast Cancer Res Treat (Epub ahead of print)

3. Fentiman IS, Fourquet A, Hortobagyi GN (2006) Male breast cancer. Lancet 367:595-604. doi:10.1016/S0140-6736(06)682 26-3

4. Zanetti R, Gafà L, Pannelli F, Conti E, Rosso S (eds) (2001) Il cancro in Italia 3. I dati dei Registri Tumori. Volume terzo: 19931998. Il Pensiero Scientifico Editore, Roma

5. Agrawal A, Ayantunde AA, Rampaul R, Robertson JF (2007) Male breast cancer: a review of clinical management. Breast Cancer Res Treat 103:11-21. doi:10.1007/s10549-006-9356-Z

6. Giordano SH (2005) A review of the diagnosis and management of male breast cancer. Oncologist 10:471-479. doi:10.1634/ theoncologist.10-7-471

7. Ferla R, Calo V, Cascio S (2007) Founder mutations in BRCA1 and BRCA2 genes. Ann Oncol 18(Suppl 6):vi93-vi98. doi: 10.1093/annonc/mdm234

8. Baudi F, Quaresima B, Grandinetti C, Cuda G, Faniello C, Tassone $\mathrm{P}$ et al (2001) Evidence of a founder mutation of BRCA1 in a highly homogeneous population from southern Italy with breast/ovarian cancer. Hum Mutat 18:163-164. doi:10.1002/ humu. 1167
9. Pisano M, Cossu A, Persico I, Palmieri G, Angius A, Casu G et al (2000) Identification of a founder BRCA2 mutation in Sardinia. Br J Cancer 82:553-559. doi:10.1054/bjoc.1999.0963

10. Russo A, Calo V, Bruno L, Schiro V, Agnese V, Cascio S et al (2008) Is BRCA1-5083del19, identified in breast cancer patients of Sicilian origin, a Calabrian founder mutation? Breast Cancer Res Treat (Epub ahead of print)

11. Malacrida S, Agata S, Callegaro M, Casella C, Barana D, Scaini MC et al (2008) BRCA1 p.Val1688del is a deleterious mutation that recurs in breast and ovarian cancer families from Northeast Italy. J Clin Oncol 26:26-31. doi:10.1200/JCO.2007.13.2118

12. Tournier I, Paillerets BB, Sobol H, Stoppa-Lyonnet D, Lidereau R, Barrois M et al (2004) Significant contribution of germline BRCA2 rearrangements in male breast cancer families. Cancer Res 64:8143-8147. doi:10.1158/0008-5472.CAN-04-2467

13. Woodward AM, Davis TA, Silva AG, Kirk JA, Leary JA (2005) $\mathrm{kConFab}$ investigators. Large genomic rearrangements of both BRCA2 and BRCA1 are a feature of the inherited breast/ovarian cancer phenotype in selected families. J Med Genet 42:e31. doi: 10.1136/jmg.2004.027961

14. Gutierrez-Enriquez S, de La Hoya M, Martinez-Bouzas C, De Abajo AS, Cajal TR, Llort G et al (2006) Screening for large rearrangements of the BRCA2 gene in Spanish families with breast/ovarian cancer. Breast Cancer Res Treat 103:103-107. doi: 10.1007/s10549-006-9376-8

15. Machado PM, Brandao RD, Cavaco BM, Eugenio J, Bento S, Nave $M$ et al (2007) Screening for a BRCA2 rearrangement in high-risk breast/ovarian cancer families: evidence for a founder effect and analysis of the associated phenotypes. J Clin Oncol 25:2027-2034. doi:10.1200/JCO.2006.06.9443

16. Walsh T, Casadei S, Coats KH, Swisher E, Stray SM, Higgins J et al (2006) Spectrum of mutations in BRCA1, BRCA2, CHEK2, and TP53 in families at high risk of breast cancer. JAMA 295:1379-1388. doi:10.1001/jama.295.12.1379

17. Falchetti M, Lupi R, Rizzolo P, Ceccarelli K, Zanna I, Calò V et al (2008) BRCA1/2 rearrangements and CHEK2 common mutations are infrequent in Italian male breast cancer cases. Breast Cancer Res Treat 110:161-167. doi:10.1007/s10549007-9689-2

18. Nahleh ZA, Srikantiah R, Safa M, Jazieh AR, Muhleman A, Komrokji R (2007) Male breast cancer in the veterans affairs population: a comparative analysis. Cancer 109:1471-1477. doi: $10.1002 /$ cncr.22589

19. Honrado E, Osorio A, Palacios J, Benitez J (2006) Pathology and gene expression of hereditary breast tumors associated with BRCA1, BRCA2 and CHEK2 gene mutations. Oncogene 25:5837-5845. doi:10.1038/sj.onc. 1209875

20. Bane AL, Beck JC, Bleiweiss I, Buys SS, Catalano E, Daly MB et al (2007) BRCA2 mutation-associated breast cancers exhibit a distinguishing phenotype based on morphology and molecular profiles from tissue microarrays. Am J Surg Pathol 31:121-128. doi:10.1097/01.pas.0000213351.49767.0f

21. Kwiatkowska E, Teresiak M, Filas V, Karczewska A, Breborowicz D, Mackiewicz A (2003) BRCA2 mutations and androgen receptor expression as independent predictors of outcome of male breast cancer patients. Clin Cancer Res 9(12): 4452-4459

22. Burga AM, Fadare O, Lininger RA, Tavassoli FA (2006) Invasive carcinomas of the male breast: a morphologic study of the distribution of histologic subtypes and metastatic patterns in 778 cases. Virchows Arch 449:507-512. doi:10.1007/s00428-0060305-3

23. Evans DG, Bulman M, Young K, Howard E, Bayliss S, Wallace A et al (2008) BRCA1/2 mutation analysis in male breast cancer families from North West England. Fam Cancer 7:113-117. doi: 10.1007/s10689-007-9153-9 
24. Syrjäkoski K, Kuukasjärvi $T$, Waltering $K$, Haraldsson $K$, Auvinen A, Borg A et al (2004) BRCA2 mutations in 154 finnish male breast cancer patients. Neoplasia 6:541-545. doi:10.1593/ neo.04193

25. Ottini L, Masala G, D’Amico C, Mancini B, Saieva C, Aceto G et al (2003) BRCA1 and BRCA2 mutation status and tumor characteristics in male breast cancer: a population-based study in Italy. Cancer Res 63:342-347

26. Parmigiani G, Berry DA, Aguilar O (1998) Determining carrier probabilities for breast cancer-susceptibility genes BRCA1 and BRCA2. Am J Hum Genet 62:145-158. doi:10.1086/301670

27. Bianchi S, Palli D, Falchetti M, Saieva C, Masala G, Mancini B et al (2006) ErbB-receptors expression and survival in breast carcinoma: a 15-year follow-up study. J Cell Physiol 206:702708. doi:10.1002/jcp. 20535

28. Dakin Haché K, Gray S, Barnes PJ, Dewar R, Younis T, Rayson D (2007) Clinical and pathological correlations in male breast cancer: intratumoral aromatase expression via tissue microarray. Breast Cancer Res Treat 105:169-175. doi:10.1007/s10549006-9448-9

29. Basham VM, Lipscombe JM, Ward JM, Gayther SA, Ponder BA, Easton DF et al (2002) BRCA1 and BRCA2 mutations in a population-based study of male breast cancer. Breast Cancer Res 4:R2. doi:10.1186/bcr419

30. Chodick G, Struewing JP, Ron E, Rutter JL, Iscovich J (2008) Similar prevalence of founder BRCA1 and BRCA2 mutations among Ashkenazi and non-Ashkenazi men with breast cancer: evidence from 261 cases in Israel, 1976-1999. Eur J Med Genet 51:141-147. doi:10.1016/j.ejmg.2007.11.001

31. Papi L, Putignano AL, Congregati C, Zanna I, Sera F, Morrone D et al (2008) Founder mutations account for the majority of BRCA1-attributable hereditary breast/ovarian cancer cases in a population from Tuscany, Central Italy. Breast Cancer Res Treat (in press). doi:10.1007/s10549-008-0190-3

32. Capalbo C, Buffone A, Vestri A, Ricevuto E, Rinaldi C, Zani M et al (2007) Does the search for large genomic rearrangements impact BRCAPRO carrier prediction? J Clin Oncol 25:26322634. doi:10.1200/JCO.2007.11.4330

33. Miolo G, Puppa LD, Santarosa M, De Giacomi C, Veronesi A, Bidoli E et al (2006) Phenotypic features and genetic characterization of male breast cancer families: identification of two recurrent BRCA2 mutations in North-east of Italy. BMC Cancer 6:156. doi:10.1186/1471-2407-6-156

34. Pich A, Chiusa L, Margarina E (1994) Proliferative activity is a significant prognostic factor in male breast carcinoma. Am J Pathol 145:481-489

35. Muñoz de Toro MM, Maffini MV, Kass L, Luque EH (1998) Proliferative activity and steroid hormone receptor status in male breast carcinoma. J Steroid Biochem Mol Biol 67:333-339. doi: 10.1016/S0960-0760(98)00124-1 